\title{
DISAIN PROTOTYPE PICK AND PLACE SISTEM PNEUMATIK MENGGUNAKAN MIKROKONTROLLER ATMEGA8535
}

\author{
Aswardi $^{1)}$, Kurniadi Lisman ${ }^{2)}$ \\ 1),2) Jurusan Teknik Elektro, Universitas Negeri Padang \\ Jln. Prof. Hamka - Air Tawar Padang 25132, Indonesia
}

email : aswardi@ft.unp.ac.id

\begin{abstract}
Abstrak
Perpindahan objek dari suatu tempat ke tenpart yang lain adalah pekerjaan yang umum dilakukan manusia setiap hari. Namun ada beberapa hal yang tidak mampu dan sangat berbahaya jika dipindahkan langsung oleh manusia seperti benda panas, tajam, berat, memancar dan lain-lain. Oleh karena itu diperlukan sebuah alat yang dapat menggantikan kerja manusia secara langsung. Selain membantu meringankan pekerjaan manusia alat ini juga diharapkan dapat meningkatkan produksi di industri. Untuk mengganti dan meringankan pekerjaan manusia dan menghindari bahaya dalam pekerjaan memindahkan barang. Penelitian ini bertujuan untuk merancang dan membuat prototipe peralatan pick and place dengan sistem pneumatik dan untuk menguji kinerja alat ini. Dalam penelitian ini peralatan pick and place sistem pneumatik berbasis mikrokontroler atmega 8535. Proses desain dimulai dari desain mekanik, termasuk kemasan kemudian merancang sirkuit listrik. Desain terdiri dari merancang catu daya listrik, sistem minimum, sirkuit masukan komponen dan komponen output. Setelah desain sirkuit listrik dibuat juga desain perangkat lunak disesuaikan dengan prinsip-prinsip dan cara kerja peralatan. Berdasarkan analisis, alat ini mampu mengangkat benda dengan massa maksimum 2,49 kg sedangkan massa benda yang digunakan berkisar antara 27,95 gram ke 33,95 gram dengan tekanan kerja minimal 6654.76 Pa ke 8.083,33 Pa. Bekerja tekanan adalah jauh di bawah tekanan kerja minimum dari tabel air slide $150.000 \mathrm{~Pa}$. Jika tekanan kerja yang lebih dari tekanan kerja yang dibutuhkan, kecepatan pneumatik akan meningkat.
\end{abstract}

Keywords; Pick and Place, Pneumatik, Mikrokontroller, photoelectric, fiberoptic

\section{Pendahuluan}

Proses pemindahkan benda merupakan pekerjaan yang setiap hari dilakukan manusia. Namun ada beberapa benda yang tidak mampu dan sangat berbahaya apabila dipindahakan langsung oleh tangan manusia seperti benda panas, tajam, berat, beradiasi dan berbagai bahaya lainya. Seiring meningkatnya kebutuhan akan otomatisasi pada peralatan baik untuk keperluan rumah tangga maupun industri. Sebagian besar peralatannya bekerja secara otomatis dikontrol menggunakan sistem kontrol yang dapat diprogram sesuai dengan kebutuhan seperti robot. Robot dapat bekerja dalam berbagai hal salah satunya adalah dalam proses memindahkan benda.

Peralatan pemindah barang yang terdapat di industri umumnya menggunakan motor listrik, hidrolik, dan pneumatik sebagai penggerak utama (aktuator). Alat pemindah barang yang menggunakan motor seperti lengan robot, beltconveyor, lift dan lain-lain. Sedangkan yang menggunakan hidrolik seperti excavator, crane dan berbagai peralatan lainya. Jenis penggerak yang digunakan tergantung kebutuhan masing-masing sistem seperti bentuk barang yang akan dipindahkan, kecepatan, keakurasian, daya angkat, tingkat kebersihan, jarak perpindahan dan lain-lain.

Beberapa alat pemindah barang yang telah dibuat dalam dalam bentuk lengan robot yang digerakkan dengan menggunakan beberapa motor, sehingga sulit dalam melakukan penyetelan ketepatan, karena harus mengatur kecepatan dan sudut putar rotor motor tersebut ${ }^{[3][9]}$. Selain itu juga kurang cepat dalam bekerja yaitu dengan kecepatan rata-rata 21,51 detik. Motor ini juga berkemungkinan besar rusak apabila putarannya tertahan. Berdasarkan permasalahan di atas maka dibuatlah alat pemindah barang pick and placeyang bekerja secara otomatis. Alat ini bekerja dengan cara mengambil dan meletakkan objek apabila sensor mendeteksi objek, maka pencengkram(gripper) akan bergerak dan mengambil objek tersebut kemudian dipindahkan dan diletakkan ke tempat tertentu. Peralatan ini dirancang lebih cepat dari peralatan sebelumnya yaitu mampu memindahkan satu objek dalam waktu 5 detik.

Sistem pemindahan barang pada industri yang berskala kecil dan industri rumah tangga seperti industri mainan dan souvenir masih banyak yang menggunakan tenaga 
manusia. Ini disebabkan karena peralatan-peralatan sistem kontrol memerlukan biaya yang cukup mahal. Oleh karena itu peralatan pemindah barang pada sistem pick and place ini dibuat menggunakan mikrokontroler Atmega 8535 sebagai sistem kontrol utama. Hal ini dikarenakan mikrokontroler Atmega 8535 jauh lebih murah jika dibandingkan dengan kontroler jenis yang lain seperti PLC (programmable logic controller) ${ }^{[1]}$.

Aktuator atau penggerak yang digunakan pada alat ini adalah sistem pneumatik. Pneumatik memiliki beberapa keunggulan dibandingkan sistem penggerak secara hidrolik. Diantaranya adalah sumber energinya terdapat dimana-mana, mudah menyimpan dan menyalurankan bahan bakunya, bersih, memiliki kecepatan tinggi, tidak perlu melakukan penyetelan kecepatan dan sudut putar melalui program.

Pneumatik menghasilkan perpindahan berdasarkan panjang piston yang dimilikinya. Jadi hanya diperlukanpenyesuaian jarak perpindahannya agar tepat pada titik yang diinginkan. Kecepatan dan tenaganya diatur hanya dengan mengatur tekanan angin melalui saluran masuk, berapapun kecepatanya jarak perpindahanya akan tetap.

Kontroler ini dibuat dalam bentuk sistem minimum yang bekerja sesuai dengan program yang menggunakan bahasa pemograman BASCOM (basic compiler). Aktuator utama dalam sistem ini adalah pneumatik yang bekerja berdasarkan sinyal output dari mikrokontroler Atmega 8535.

Namun terdapat beberapa kendala dalam pembuatan peralatan ini seperti biaya dan waktu pembuatan. Oleh karena itu penelitian ini dibuat dalam bentuk prototype pick and place dengan sistem pneumatik berbasis mikrokontroler Atmega 8535. Lebar pencengkraman 40 $\mathrm{mm}$ sampai $50 \mathrm{~mm}$ dan jarak perpindahan $200 \mathrm{~mm}$.

Sistem kontrol lup terbuka memiliki keluaran yang tidak dibandingkan dengan masukan acuan atau hasil keluaran tidak mempengaruhi aksi kontrol. Sehingga untuk setiap masukan acuan terdapat suatu kondisi operasi yang tetap. Jadi ketelitian sistem bergantung pada kalibrasi yang harus hati-hati dilakukan. Sistem kendali terbuka dapat digunakan hanya jika hubungan antara input dan output diketahui secara pasti dan tidak terdapat gangguan internal maupun eksternal.

Sistem kontrol lup terbuka adalah sistem kontrol yang keluarannya tidak berpengaruh pada aksi pengontrolan. Jadi pada sistem kontrol lup terbuka, keluaran tidak diukur atau diumpan- balikan untuk dibandingkan dengan masukan",[5].

Mikrokontroler merupakan otak dari suatu sistem kontrol yang memanfaatkan teknik elektronika. Mikrokontroler dapat ditulis dan dihapus atau diprogram ulang. Mikrokontroler dikemas dalam bentuk IC yang didalamnya terdapat memori (RAM/ROM) dan sistem input/putput. Mikrokontroler Atmega 8535 dipilih untuk untuk mengontrol sistem kerja peralatan sistem pick and place ini, disebabkan Mikrokontroler Atmega 8535 memiliki memori yang cukup, dan fitur-fitur yang cocok digunakan untuk mengontrol sistem kerja alat

Sistem pneumatik atau sistem udara adalah suatu sistem yang memanfaatkan udara untuk menghasilkan suatu kerja. Sistem pneumatik dengan udara yang bertekanan banyak digunakan untuk meringankan tenaga manusia.Sistem pneumatik merupakan bagian paling utamapada peralatan ini, karena semua elemen penggerak menggunakan pneumatik. Semua sistem yang menggunakan tenaga yang disimpan dalam bentuk udara yang dimampatkan untuk menghasilkan suatu kerja disebut sistem pneumatik ${ }^{[8]}$ ".

Aktuator pneumatik memiliki arah gerak maju (langkah maju) dan arah gerak mundur (langkah mundur). Tekanan udara yang bekerja dalam silinder menyebabkan batang piston bergerak maju atau mundur. Jika tekanan pada sisi berlawanan diabaikan maka besarnya gaya yang bekerja pada piston adalah:

$F=p x A$

Pada langkah maju gaya dipengaruhi oleh luas penampang silinder dan luas penampang silinder tergantung pada diamter dalam.

$A=\frac{\pi}{4} D^{2}$

Gaya langkah maju yang bekerja pada silinder sebagai berikut:

$F=\frac{\pi}{4} D^{2} \cdot p$

Besarnya gaya pada langkah mundur dipengaruhi diameter dalam silinder dan diameter luar batang piston.

$A=\frac{\pi}{4}\left(D^{2}-d^{2}\right)$

Sehingga gaya langkah mundur yang bekerja pada silinder adalah:

$F=p \cdot \frac{\pi}{4}\left(D^{2}-d^{2}\right)$

Setelah didapatkan besarnya gaya yang bekerja pada silinder maka besarnya massa benda yang mampu didorong silinder dihitung menggunakan dengan :

$\mathrm{F}=\mathrm{m} \times \mathrm{g}$

$\mathrm{m}=\mathrm{F} / \mathrm{g}$

Jika massa benda telah ditentukan, maka besarnya tekanan terkecil yang diberikan untuk mendorong pneumatik, agar pneumatik mampu mendorong benda dihitung persamaan;

$\mathrm{p}=\mathrm{F} / \mathrm{A}$

$\mathrm{p}=(\mathrm{m} \times \mathrm{g}) / \mathrm{A}$ 


\section{Komponen Utama Sistem}

Katup 5/2 solenoid tunggal mempunyai pegas untuk mengembalikan katup ke posisi netral.

\section{Prinsip Kerja Katup 5/2 Solenoid Tunggal}

Posisi Awal

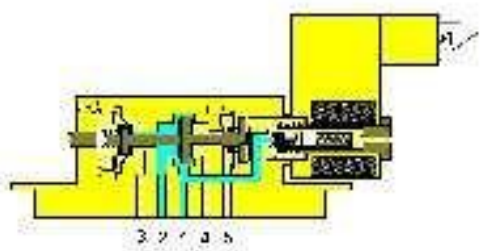

Posisi Aktif

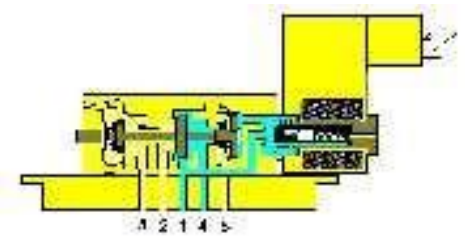

Gambar 1. Prinsip kerja katub 5/2 solenoid tunggal

Katup 5/2 solenoid ganda memiliki 2 solenoid dan tidak memiliki pegas pengembali.Mengaktifkan katup ke posisi yang diinginkan dengan memberi tegangan pada salah satu solenoid yang akan mengaktifkan katup tersebut.

\section{Prinsip Kerja Katup 5/2 Solenoid Ganda}

- $\quad$ Posisi $Y_{2}$ terakhir aktif

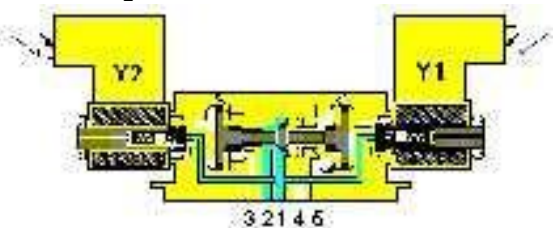

- Posisi $Y_{1}$ aktif

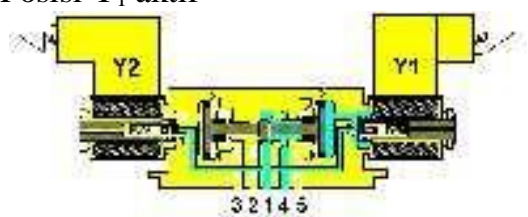

Gambar 2. Prinsip kerja katub 5/2 solenoid ganda

UnitFilter-Regulator-Lubricator(FRL) merupakan salah satu komponen yang penting dalam sistem pneumatik. FRL terpasang pada tiap sambungan pneumatik menyiapkan pengguna dengan pertahanan terakhir melawan kontaminasi pada udara yang akan dipakai.

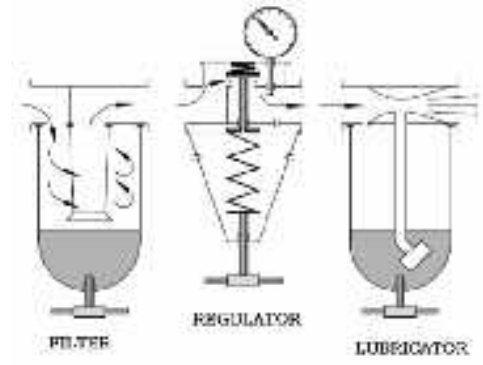

Gambar 3. Prinsip kerja FRL

Reed switch adalah sensor yang bekerja berdasarkan pada medan magnet yang dipasang pada piston silinder pneumatik.

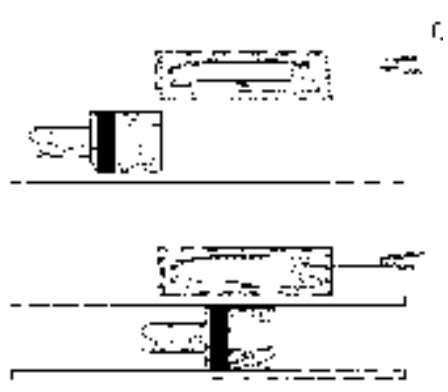

Gambar 4. Prinisip kerja Reed switch

Alat penggerak berupa silinder, biasanya dilengkapi dua buah sensor ini, yang berfungsi untuk mendeteksi gerakan silinder ketika naik atau turun, letaknya ada di bagian luar bawah dan luar atas pada silinder.

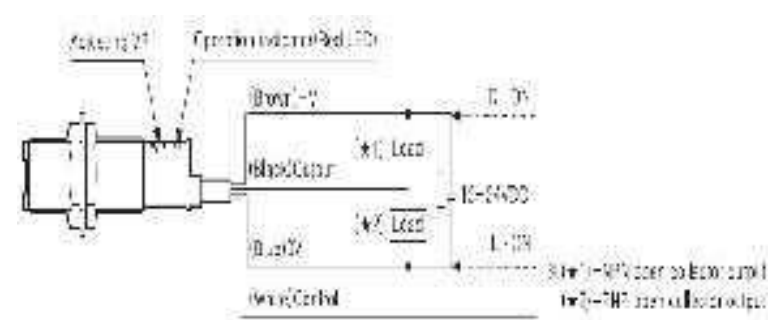

Gambar 5. Pengawatan photoelectric sensor

Fiberoptic sensor yang akan dipakai adalah tipe difusi sama seperti sensor photoelectric di atas. Sensor ini nantinya dipasang untuk mendeteksi apakah gripper pneumatik sudah mengenggam objek kerja.

\section{Metode Perancangan}

Tahapan perancangan peralatan meliputi perancangan blok diagram dan perancangan rangkaian elektrik. 
1. Perancangan Peralatan

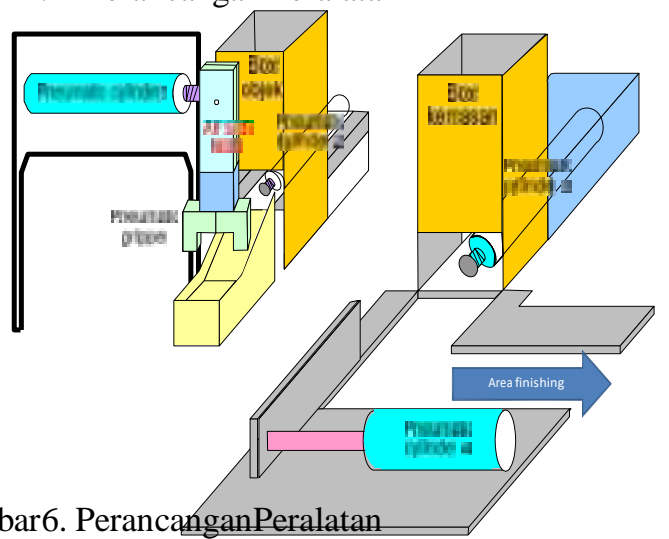

2. Perancangan Blok Diagram

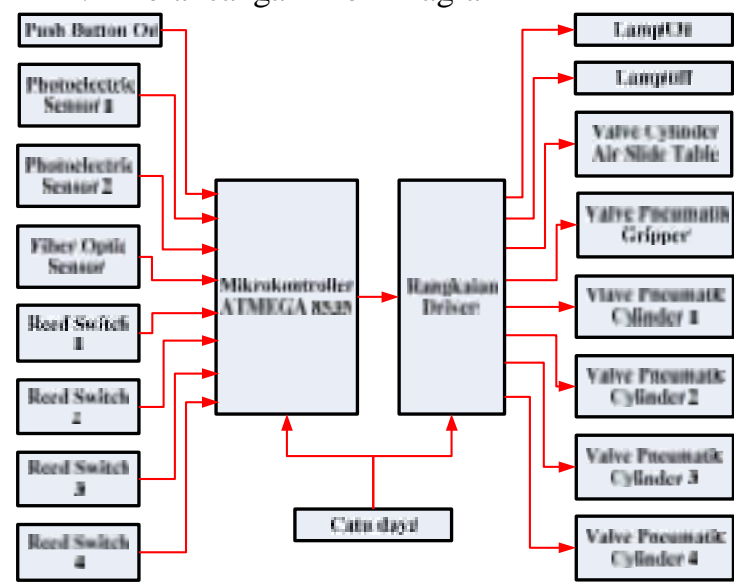

Gambar7. Blok diagram Sistem

3. Rangkaian Catu daya

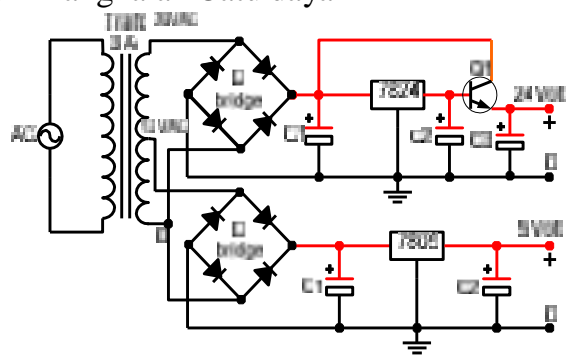

Gambar8. Rangakaiancatudaya

Catu daya 24 volt de diambil dari keluaran 30 volt dan disearahkan oleh dioda (IN5401, 3A), difilter dengan Elco

$4700 \mu$ F/50 V. IC LM7824 dipasang C2 $1000 \mu$ F/50 Volt dan transistor Q1 sebagai penguat daya

4. Rangkaian Sistem Minimum

Rangkaian sistem minimum merupakan rangkaian untuk mengaktifkan mikrokontroler Atmega 8535.. Rangkaian sistem minimum terdiri dari Atmega 8535, 2 buah kapasitor $22 \mathrm{pF}$ dan kristal $16 \mathrm{MHz}$.

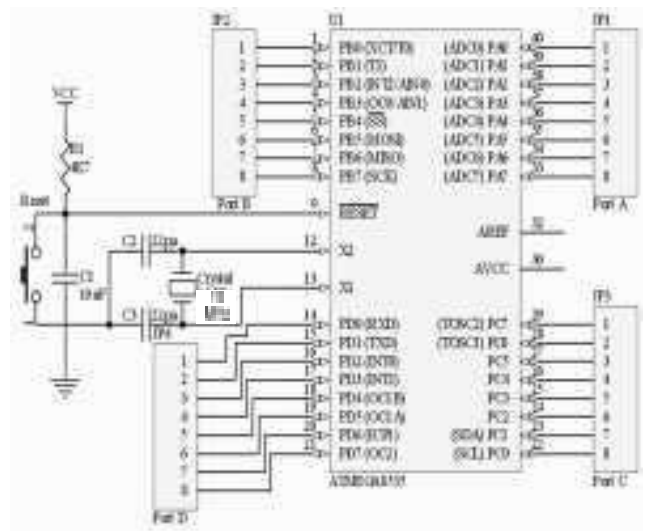

.Gambar9. Sistem minimum

Kristal ini akan mempengaruhi kecepatan mikrokontroler ATMega 8535 saat mengeksekusi perintah. Pin 9 merupakan masukan reset (aktif rendah).

\section{Hasil dan Pembahasan}

Setelah pengujian dan pengukuran dilakukan didapatkan hasil pengukuran diameter silinder diperlihatkan pada tabel berikut.

TABEL I DATA PNEUMATIK

\begin{tabular}{|c|c|c|c|c|c|}
\hline $\mathrm{N}$ & \multirow{2}{*}{ Aktuator } & \multirow{2}{*}{$\begin{array}{l}\mathrm{D} \\
(\mathrm{nm})\end{array}$} & \multirow{2}{*}{$\begin{array}{l}\mathrm{D} \\
(\mathrm{mm})\end{array}$} & \multicolumn{2}{|c|}{$\mathrm{p}(\mathrm{MPa})$} \\
\hline 0 & & & & Min & Maks \\
\hline 1 & Silinder 1 & 34 & 13 & 0,15 & 0,8 \\
\hline 2 & Silinder 2 & 15,5 & 6 & 0,15 & 0,8 \\
\hline 3 & Silinder 3 & 20 & 10 & 0,15 & 0,8 \\
\hline 4 & Silinder 4 & 15,5 & 6 & 0,15 & 0,8 \\
\hline 5 & Air slide table & $\begin{array}{l}57 \\
\mathrm{~mm}^{2}\end{array}$ & $42 \mathrm{~mm}^{2}$ & 0,15 & 0,7 \\
\hline 6 & Gripper & $4 \mathrm{~mm}^{2}$ & $4 \mathrm{~mm}^{2}$ & 0,15 & 0,7 \\
\hline
\end{tabular}

Besar gaya angkat maksimum sama dengan besar gaya langkah mundur maksimum, yaitu 29,4 N. Besar gaya angkat minimum sama dengan besar gaya langkah mundur minimum yaitu 6,3 N. Jika tekanan yang diberikan pada air slide table adalah tekanan maksimum $(0,7 \mathrm{MPa})$ maka maksimal beban yang dapat diangkat adalah 2.490 gram.

Berdasarkan data yang didapatkan pada tabel data pneumatik diperoleh analisa pada pneumatik sebagai berikut.

Tabel II Hasilanalisapneumatik

$$
\text { Gaya langkah Gaya langka }
$$

Aktuator maju(N)

\begin{tabular}{lllll} 
& Min & Maks & Min & Maks \\
\cline { 1 - 5 } Silinder 1 & 136,11 & 725,96 & 116,21 & 619,83 \\
\hline Silinder 2 & 28,29 & 150,87 & 24,05 & 128,26 \\
\hline $\begin{array}{llll}\text { Silinder 3 } \\
\text { Silinder 4 }\end{array}$ & 47,1 & 251,2 & 35,32 & 45,216 \\
\cline { 1 - 5 } $\begin{array}{l}\text { Air slide } \\
\text { table }\end{array}$ & 8,55 & 150,87 & 24,05 & 128,26 \\
\cline { 1 - 5 } gripper & 0,6 & 2,8 & 0,6 & 29,4 \\
\hline
\end{tabular}


Jika tekanan yang diberikan pada air slide table adalah tekanan minimum $(0,15 \mathrm{MPa})$ maka maksimal beban

yang dapat diangkat adalah 630 gram. Jika lebih dari 630 gram maka air slide table tidak mampu mengangkat beban tersebut.

Objek digunakan pada penelitian ini adalah 5 buah dengan lebar objek diantara rentang cengkraman gripper

yaitu 40-50. Hasil pengukuran massa objek dapat dilihat pada tabel berikut ini.

\begin{tabular}{lll}
$\begin{array}{l}\text { Tabel III Massa objek } \\
\text { Nomor }\end{array}$ & Massa Objek & A2 \\
Objek & (gram) & air slide table \\
\hline 1 & $\frac{27,95}{30,30}$ & \\
\hline 2 & 30,50 & \\
3 & 33,40 & $\mathrm{~mm}^{2}$ \\
\hline 5 & 33,95 & \\
\hline
\end{tabular}

Besarnya tekanan kerja minimal yang harus diberikan pada air slide table tergantung pada massa benda yang akan diangkat. Semakin berat massa benda atau objek yang akan diangkat maka semakin besar pula gaya yang harus diberikan pada air slide table.

Tabel IV Hasiltekananpneumatik

\begin{tabular}{lll}
$\begin{array}{l}\text { Nomor } \\
\text { Objek }\end{array}$ & $\begin{array}{l}\text { Massa Objek } \\
\text { (gram) }\end{array}$ & Tekanan \\
\hline 1 & 27,95 & $6.654,76 \mathrm{~Pa}$ \\
\hline 2 & 30,30 & $7.219,04 \mathrm{~Pa}$ \\
\hline 3 & 30,50 & $7.261,90 \mathrm{~Pa}$ \\
\hline 4 & 33,40 & $7.952,38 \mathrm{~Pa}$ \\
\hline 5 & 33,95 & $8.083,33 \mathrm{~Pa}$ \\
\hline
\end{tabular}

Tekanan kerja minimal yang dibutuhkan air slide table untuk mengangkat objek adalah 6.654,76 Pa sampai 8.083,33 Pa. Tekanan ini dibawah tekanan kerja minimum air slide table yaitu 0,15 MPa atau $150.000 \mathrm{~Pa}$. Jika air slide table diberi tekanan sesuai dengan massa objek yaitu dari 6.654,76 Pa sampai 8.083,33 Pa maka air slide table tidak akan bekerja. Agar air slide table tetap dapat bekerja maka air slide table diberi tekanan mulai dari 0,15 MPa sampai 0,7 MPa.

Pada tekanan minimum $(0,15 \mathrm{MPa})$, air slide table mampu mangangkat beban maksimal atau paling berat 630 gram. Sedangkan massa rata-rata objek yang digunakan pada penelitian ini adalah berkisar dari 27,95 gram sampai 33,95 gram. Berarti dari maksimal kemampuan air slide table mengangkat objek baru berkisar 4,43\% sampai 5,38\%. Massa objek ini jauh dibawah massa ideal maksimal kemampuan air slide table pada saat diberi tekanan minimum. Namun pada massa dibawah massa ideal tersebut objek tetap dapat di angkat oleh air slide table dengan pergerakan yang lebih cepat.
Tabel V Percobaan TiNGKAT presisi

\begin{tabular}{lll}
\hline No & $\begin{array}{l}\text { Percobaan } \\
\text { objek }\end{array}$ & Waktu total \\
\hline 1 & pertama & Berhasil \\
\hline 2 & kedua & Berhasil \\
\hline 3 & ketiga & Berhasil \\
\hline 4 & keempat & Berhasil detik \\
\hline 5 & kelima & Berhasil \\
\hline
\end{tabular}

Kecepatan pneumatik saat memindahkan objek dipengaruhi oleh besar tekanan angin, massa objek dan luas penampang piston. Dalam proses pemindahan objek yang dimulai dari mendorong objek sampai menarik

kemasan yang berisi objek ke area finishing dan kembali ke posisi semula.Prototype ini dapat bekerja dalam waktu 30 detik untuk 5 buah objek. Jadi rata-rata waktu untuk

memindahkan satu objek adalah 6 detik maka sistem pneumatik pada Penelitian ini lebih cepat dalam

memindahkan barang dibandingkan alat pemindah barang sebelumnya yang menggunakan motor yaitu hanya 21,51 detik.

Prototype ini dibuat untuk menampung 5 objek kerja dalam 1 siklus.Jadi untuk mendapatkan hasil sesuai dengan tujuan selanjutnya hasil dari pengujuan kecepatan dikalkulasikan untuk mendapatkan jumlah objek yang dapat dipindahkan setiap detiknya. Setelah dilakukan

perhitungan selama pengujian, diperoleh bahwa prototype

ini dapat melakukan proses pemindahan objek mulai dari mendorong objek ke area kerja, mengangkat objek, membawa objek ke tempat kemasan, melepas objek, dan terakhir menarik objek beserta kemasannya ke finishing area dan kembali ke posisi standby diperlukan waktu 25 detik untuk 5 buah objek kerja beserta kemasannya, jadi rata-rata tiap 1 objek dan kemasannya dapat dipindahkan dalam waktu 5 detik.

Dari 5 kali pegujian yang dilakukan, semua objek berhasil dipindahkan dengan baik, tepat dan pas masuk ke dalam kemasan yang disediakan. Ini ditunjukkan bahwa alat yang dibuat ini dapat memindahkan objek ke dalam kemasannya dengan cepat dan tepat. Dengan hasil pengujian bahwa 1 objek dipindahkan dalam waktu 5 detik didapatlah bahwa dalam satu menit prototype ini dapat memindahkan objek kerja sebanyak 12 buah.

Untuk mengetahui besarnya daya angkat maksimum dan minimum alat ini dapat dilihat dari besarnya gaya yang dihasilkan oleh pneumatik air slide table. Daya angkat ini ditunjukkan ketika pneumatik air slide table dalam kondisi langkah mundur. Berdasarkan rumus $\mathrm{F}=\mathrm{m} . \mathrm{g}$ dimana $\mathrm{F}$ adalah besarnya gaya yang dihasilkan, $\mathrm{m}$ mewakili masa objek dan $\mathrm{g}$ mewakili percepatan gravitasi yang bernilai konstan $9,8 \mathrm{~m} / \mathrm{s}^{2}$. Besarnya tekanan minimum yang diperlukan untuk menggerakkan pneumatik air slide 
Menggunakan daya angkat maksimum ketika tekanan minimum adalah $6,32 \mathrm{~N} / 10 \mathrm{~m} / \mathrm{s}^{2}$ atau $0,632 \mathrm{~kg}$

Sedangkan daya angkat maksimum ketika tekanan udara yang masuk ke pneumatik air slide table juga bernilai maksimum, yaitu sebesar 0,7 MPa. Dengan gaya yang dihasilkan sebesar 33,6 N, nilai daya angkat maksimum ketika tekanan udaranya maksimum adalah.29,4 N=m $\mathrm{x} 10 \mathrm{~m} / \mathrm{s}^{2}$ akan diperoleh $\mathrm{m}=2.94 \mathrm{~kg}$

Jadi ketika tekanan udara minimum sebesar 0,15 $\mathrm{MPa}$ daya angkat maksimumnya adalah $0,632 \mathrm{~kg}$, sedang ketika tekanan udara maksimum sebesar $0,7 \mathrm{MPa}$ daya angkat maksimumnya adalah $2,94 \mathrm{~kg}$.

\section{Kesimpulan}

Setelah melakukan pengujian dan analisa rangkaian Prototype Pick and Place dengan, maka diperoleh kesimpulan; 1) Untuk memindahkan objek dengan massa 27,95 gram sampai 33,95 gram dibutuhkan tekanan kerja minimal 6.654,76 $\mathrm{Pa}$ sampai 8.083,33 Pa. Sedangkan tekanan kerja minimum alat adalah $150.000 \mathrm{~Pa}$, sehingga untuk memindahkan objek tersebut harus diberikan tekanan minimum kerja alat.2) Waktu yang digunakan untuk memindahkan sebuah objek adalah 6 detik.

Dari proses tersebut didapatkan beberapa saran yang diharapkan bermanfaat untuk mengembangkan sistem ini: 1) untuk menghilangkan kebisingan maka sebaiknya setiap pneumatik diberi peredam. 2) agar dapat memindahkan objek lebih dari satu posisi, gunakan katub $5 / 3$ dan sensor yang dapat membedakan jenis objek

\section{Referensi}

[1] Aswardi, 2015. Disain Prototype Pick and Place Sistem Pneumatic Menggunakan PLC Omron CPE1. Prosiding Seminar Fortei, Univ Tanjung Pura.

[2] Barber, Anthony. 1997. "Pneumatic Handbook $8^{\text {th }}$ Edition". England: Elsevier Science \& Technology Books

[3] Deri Furqon. 2009. "Perancangan dan Pembuatan Kontrol Lengan Robot Berbasis Mikrokontroler AT89S51". Proyek Akhir Jurusan Teknik Elektro Universitas Negeri Padang.

[4] F. Ebel, P. Croser. 2002. "Pneumatic Basic Level" Germany: Festo Didactic

[5] Katsuhiko, Ogata. 1995. "Teknik Kontrol Automatik (Sistem Pengaturan)". (Edi Laksono. Tejemahan). Jakarta: Erlangga

[6] Krist, Tomas. 1993. "Dasar-Dasar Pneumatik". (Purnomo Wahyu Indarto. Terjemahan). Jakarta: Erlangga. Buku asli diterbitkan tahun 1979.

[7] Nurcahyo, Sidik. 2012. "Aplikasi dan Teknik Pemograman Mikrokontroler AVR Atmel". Yogyakarta: CV Andi Offset.

[8] Said, Hanif. 2012. "Aplikasi PLC dan Sistem Pneumatik pada Manufaktur Industri”. Yogyakarta: Andi

[9] Sepriadi. 2011. "Perancangan dan Pembuatan Lengan Robot Pendeteksi dan Pemindah Barang berbasis Mikrokontroler BASIC Stamp 2040". Proyek Akhir Jurusan Teknik Elektro Universitas Negeri Padang.

[10] Setiawan, Afrie. 2011. "20 Aplikasi Mikrokontroler ATMega8535 \& ATMega16 menggunakan bascomAVR". Yogyakarta: CV Andi Offset.

[11]Wardhana, Lingga. 2006. "Belajar Sendiri Mikrokontroler AVR Seri ATMega8535". Yogyakarta: CV Andi Offset.

[12] Yogaswara, Eka. 2012. "Proses Dasar Pneumatik dan Hidraulik". Bandung: Armic 